\title{
Comparison of Risk Factors of Stroke and Myocardial Infarction in Patients 15 to 45 Years in Affiliated Hospitals of Babol University of Medical Sciences
}

\author{
Alijan Ahmadi Ahangar,, ${ }^{1,}$ Mehrdad Saravi, ${ }^{2}$ Shayan Alijanpour, ${ }^{3}$ Mostafa Mostafazadeh Boora, ${ }^{4}$ \\ Samaneh Hoseinalipour, ${ }^{5}$ Hamed Hossein Zadeh, ${ }^{5}$ and Hemat Allah Gholinia ${ }^{5}$ \\ ${ }^{1}$ Mobility Impairment Research Center, Babol University of Medical Sciences, Babol, Iran \\ ${ }^{2}$ Department of Cardiology, Ayatollah Rouhhani Hospital, Babol University of Medical Sciences, Babol, Iran \\ ${ }^{3}$ Emergency Medical Services Center, Babol University of Medical Sciences, Babol, Iran \\ ${ }^{4}$ Isfahan University of Medical Sciences, Isfahan, Iran \\ ${ }^{5}$ Ayatollah Rouhani Hospital, Babol University of Medical Sciences, Babol, Iran \\ "Corresponding author: Alijan Ahmadi Ahangar, Mobility Impairment Research Center, Babol University of Medical Sciences, Babol, Iran. Tel: +98-9111111202, E-mail: \\ ahmadiahangaralijan@yahoo.com
}

Received 2016 January 09; Revised 2016 April 17; Accepted 2016 December 06.

\begin{abstract}
Background: Myocardial infarction (MI) and stroke are the second and third leading causes of death in the world. By identifying the risk factors we can take the necessary measures to prevent the occurrence of these diseases.

Methods: In this retrospective study, 90 MI patients and 90 stroke patients 15 - 45 year admitted to hospitals of Babol University of Medical Sciences that randomly arranged by the time of hospitalization conducted. Demographics, laboratory test and risk factors were collected using check list. The data analyzed with McNemar and Npar tests by using SPSS 21 version software.

Results: The most common risk factor in young patient was a history of cerebrovascular disease that in stroke was 31 cases (34\%) And in MI was 33 cases (37\%). History of cerebrovascular disease with MI was significant 33 (37\%), 57(63\%), P=0.047). A history of cardiovascular disease with stroke was significant (20 (22\%), 70 (68), P = 0.001). A history of addiction with MI was significant (23 (26\%), 67 (74\%), P < 0.001). In stroke patients 52 cases (\% 57) low-density lipoprotein (LDL) was high and in 66 cases (73.1\%) highdensity lipoprotein (HDL) was low. In patients with MI in 46 patients (51\%) LDL was high and the 66 patients (73\%) HDL was low.

Conclusions: Young peoples with a history of cerebrovascular, cardiovascular disease and addictions should be considering as target society. Primary health care system must identify high-risk individuals, and policy barriers that prevent implementation of programs to lower death rate.
\end{abstract}

Keywords: Myocardial Infarction, Stroke, Risk Factor

\section{Background}

Myocardial infarction (MI) and strokes are the second and third leading causes of death in the world. In relation to the importance of cardiovascular disease, it should be noted that the cost of cardiovascular disease in the United States in 2010 is estimated at 444 billion dollars [1]. MI is a leading cause of morbidity and mortality worldwide. It is an extreme manifestation of coronary artery disease. The American Heart Association reports that approximately 600,000 new patients sustain MI [2]. Young people (younger than 45 years) $4 \%$ to $7 \%$ of acute MI formed mainly occurs in men [3]. Data on the epidemiology of stroke, patterns and risk factors in Iran are brief and scattered [4-6]. Hypertension, smoking, and diabetes and ischemic heart disease are the main risk factors for stroke in Asia [7]. Smoking is a major risk factor for stroke and cardiovascular disease even in Asian countries [8, 9]. Ap- proximately $90 \%$ of all cases of MI are the result of acute occlusive thrombus in coronary artery [2]. Cardiovascular risk factors such as hypertension, hyperlipoproteinaemia, diabetes and smoking, are well accepted [10]. Reasons of myocardial infarction in young adults less than 45 divided into 4 groups. In first group "atherosclerosis classic risk factors, and especially such as smoking, increased levels of triglycerides and low HDL" [11]. In second group nonatherosclerotic causes such as congenital heart anomalies, less than $4 \%$ of acute myocardial infarctions, coronary artery dissection, and lupus and Kawasaki syndrome [12]. "Drug abuse such as "cocaine, amphetamines, morphine and other drugs that can cause heart and brain vascular accident" are in third group [13]. In last group "Hypercoagulable states: antiphospholipid syndrome, factor 5 deficiencies" and others are rare $[14,15]$. Although many risk factors for strokes and MI are similar together, it is somewhat 
different in young patients than in adults $[16,17]$. Studies show that young patients with more than three risk factors have a high probability for severe heart and brain disease [18]. In this age group the incidence of these diseases and their complications, psychological impact, a significant financial burden to families created due to these factors. Understanding the risk factor of Stroke and MI of this age is one of the most important aspects of the preventive epidemiology. It is important to recognize these patients for the purpose of risk factor modification and secondary prevention in younger patients [19]. Determine the prevalence and causes of strokes and MI risk factors in young people in the region can very valuable.

\section{Objectives}

By identifying the risk factors that we can take the necessary measures to prevent the occurrence of these diseases greatly and provide the treatment of such diseases. Therefore, this study was conducted.

\section{Methods}

This retrospective study was conducted on patients with MI and ischemic stroke. This census study on 15 - 45 years patient from 2008 to 2013 that admitted to hospitals of Babol University of Medical Sciences, was conducted. All stroke or MI cases admitted to the hospitals in the Babol were registered. Exlusion crieteria was considered and finally 180 patients entered in this study. 90 patients ranging from 45 - 15 years with a diagnosis of stroke and 90 patients in the same age range with a diagnosis of MI were studied. Stroke was defined as rapidly developing focal symptoms and signs of cerebral function that correlate with the area of the brain supplied by the affected blood vessel, lasting longer than 24 hours. Stroke was diagnosed by a neurologist, based on the patient's history, neurological examination and neuroimagings studies which was performed for all stroke patients. Stroke patients ranging from 45 - 15 years were including in study. We include ischemic stroke cases in this study and exclude hemorrhagic stroke patients. Other exclusion crieteria for stroke cases, were hemiparesis or focal neurological findings due to head trauma, metabolic encephalopathies, brain mass lesions such as brain tumor or brain abscess, hemiplegic migraine attack and postictal of seizures. Diagnostic of MI was based on chest pain similar to angina but more intense and persistent; not fully relieved by rest or nitroglycerin, often accompanied by nausea, sweating, apprehension [20]. ST elevation, followed by T-wave inversion, then Q-wave development over several hours in E.C.G. and cardiac biomarkers (CK-MB) and cardiac-specific troponins $\mathrm{T}$ and I serum level rising were para clinical documentation. The following well-documented risk factors were considered: hypertension (HTN), diabetes melituse, dyslipidemia, addiction (include opiate addiction, alcoholism and amphetamine, cocaine abuse (oral, I.V.) and smoking (nicotine), at least 5 cigarettes per day. History of addiction was determined by self-reporting of patients or their relatives who indicate continuous use of these substance and drugs at least in last year [21]. History of cerebrovascular disease, cardiovascular disease in patient and in their family has obtained as a risk factor for occurrence of stroke, MI. Demographics and risk factors were collected using check list. LAB data: C. B .C, E.S.R. Fasting blood sugar levels (FBS), cholesterol (LDL, HDL), triglycerides (TG), blood urea nitrogen (BUN), serum creatinine (CR), liver function tests: alanine transaminase(ALT), aspartatae transaminase (AST) and alkaline phosphatase (ALP) were collected and recorded. Then cut points were defined. HTN was defined as systolic blood pressure (SBP), $140 \mathrm{~mm} \mathrm{Hg}$ or diastolic blood pressure (DBP), $85 \mathrm{~mm} \mathrm{Hg}$. BUN (7 - $25 \mathrm{mg} / \mathrm{dL}$ ), CR (0.5 - $1.7 \mathrm{mg} / \mathrm{dL}:)$, ALT (45 U/L), AST (40 U/L), ALP (36 - 120 $\mathrm{U} / \mathrm{L}$ ) were defined. Low HDL was identified by HDL cholesterol $40 \mathrm{mg} / \mathrm{dL}$ in men or $50 \mathrm{mg} / \mathrm{dL}$ in women, LDL > 130 $\mathrm{mg} / \mathrm{dL}$; High TG was identified based on triglycerides150 $\mathrm{mg} / \mathrm{dL}$ and $\mathrm{FBS} \geq 110 \mathrm{mg} / \mathrm{dL}[22,23]$. Then data analyzed with McNemar and Npar tests by using SPSS 21 statistical software. $\mathrm{P}<0.05$ was considered significant.

\section{Results}

The mean age of patients with Stroke and MI was 33.7 $\pm 8,35.4 \pm 9.1$ years .Distribution of sex in both Stroke and MI group was similar 46 (54.4\%) male Stroke patients vs. 33 (55\%) male MI patients). The risk factors of stroke and MI patients were shown in Tables 1 and 2. A history of cerebrovascular disease was the most common risk factor for two groups that in stroke, 31 cases (34\%) and MI, 33 cases (37\%) was observed. History of cerebrovascular disease with MI was significant 33 (37\%), 57(63\%), P = 0.047). Also History of cardiovascular disease with stroke was significant (20 (22.3\%), 70 (77.7\%), P = 0.001). History of addiction with MI was significant (23 (26\%), 67(74\%), P $<0.001)$. In stroke patients studied in 52 cases (\% 57.2) low-density lipoprotein (LDL) was high and in 66 cases (73.1\%) high-density lipoprotein (HDL) was low. In patients with MI in 46 patients (51\%) LDL was high and the 66 patients (73\%) HDL was low. Laboratory findings of stroke and MI patients were shown in Table 3. Other risk factors had not a significant relationship with MI and stroke. 
Table 1. Statistical Analysis of Young Stroke Patient's Risk Factor

\begin{tabular}{|c|c|c|c|c|c|c|c|}
\hline $\begin{array}{l}\text { Cases of Myocardial } \\
\text { Infarction }\end{array}$ & History of Disease & Drug Abuse & Addiction & $\begin{array}{c}\text { Cerebrovascular } \\
\text { Disease }\end{array}$ & Diabetes & $\begin{array}{c}\text { Cardiovascular } \\
\text { Disease }\end{array}$ & Hypertension \\
\hline \multirow{2}{*}{ Male } & Not & $35(71)$ & $29(59)$ & $36(73)$ & $44(90)$ & $44(90)$ & $40(82)$ \\
\hline & Yes & $14(29)$ & $20(41)$ & $13(37)$ & $5(10)$ & $5(10)$ & $9(8)$ \\
\hline \multirow{2}{*}{ Female } & Not & $36(87)$ & $38(93)$ & $21(52)$ & $37(90)$ & $40(97)$ & $32(78)$ \\
\hline & Yes & $5(3)$ & $3(7)$ & $20(48)$ & $4(10)$ & $1(3)$ & $9(22)$ \\
\hline $\begin{array}{l}\text { Total abnormal } \\
\text { patient }\end{array}$ & 90 & $19(21)$ & $23(25)$ & $33(37)$ & $9(10)$ & $6(6.6)$ & $18(20)$ \\
\hline Significant level & Pvalue & 0.072 & 0 & 0.047 & 0.9 & 0.214 & 0.793 \\
\hline
\end{tabular}

Table 2. Statistical Analysis of Young MI Patient's Risk Factor

\begin{tabular}{|c|c|c|c|c|c|c|c|}
\hline Strokes Cases & History of Disease & Drug Abuse & Addiction & $\begin{array}{c}\text { Cardiovascular } \\
\text { Disease }\end{array}$ & Diabetes & $\begin{array}{c}\text { Cerebrovascular } \\
\text { Disease }\end{array}$ & Hypertension \\
\hline Male & Not & $36(78)$ & $35(77)$ & $30(65)$ & $40(86)$ & $36(78)$ & $41(89)$ \\
\hline \multirow{2}{*}{ Female } & Not & $36(81)$ & $30(68)$ & $40(90)$ & $36(87)$ & $23(56)$ & $40(90)$ \\
\hline & Yes & $8(19)$ & $11(32)$ & $4(10)$ & $8(18)$ & $21(47)$ & $4(10)$ \\
\hline $\begin{array}{l}\text { Total abnormal } \\
\text { patient }\end{array}$ & 90 & $18(20)$ & $22(25)$ & $20(22)$ & $14(15)$ & $31(35)$ & $22(24)$ \\
\hline Significant level & Pvalue & 0.47 & 0.89 & 0.002 & 0.47 & 0.11 & 0.89 \\
\hline
\end{tabular}

Table 3. Laboratory Findings in Stroke and MI Young Patients

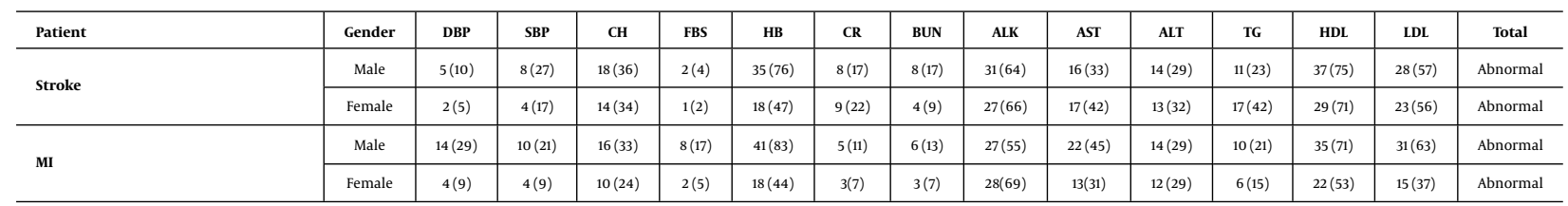

\section{Discussion}

The mean age of young patients with a diagnosis of MI and Stroke were similar together and more common in men in two groups. In a study of Sastry et al. [24] in Canada, 101 young patients with the diagnosis of MI and 101 young patients with a diagnosis of stroke at the age of 16 - 40 years considered. They were included 70 cases $(70 \%)$ of young men with a diagnosis of MI and 43 cases (43\%) with a diagnosis of stroke. In the study of Putaala et al. [25] mention that risk factor accumulation along aging and in males. This was consistent with our results. It seems that males in most studies, a greater proportion of the patients to be allocated.

History of cerebrovascular disease with MI was significant. MI in young patients is slightly higher than stroke patients. History of cerebrovascular disease can be an important risk factor for MI and also for strokes. In particular, in our study, the most common risk factor for both MI and stroke patients was a previous history of cerebrovascular disease.

A history of cardiovascular disease with stroke was significant. In a study of Ihle-Hansen [26] in 210 patients with stroke 49 patients (23\%) had a history of cardiovascular disease. In Siegerink et al. [27] study that was conducted in young women, History of cardiovascular disease and stroke among young women with MI and strokes was significant. That's similar to our studies. Based on these findings, a history of heart disease in stroke patients was higher in male patients. That indicates that males with a history of heart disease can be a predictor of stroke risk factors.

History of addictions was higher than in stroke patients. History of addiction with MI was significant. Addiction is uniformly the common risk factor in young MI pa- 
tients, with an incidence ranging from $61 \%$ to $93 \%$ in various studies (18). The study of Putaala et al. [25] in 990 patients with stroke 442 (45\%) patients had a history of addictions. In the study of Ihle-Hansen [26] in 210 patients with stroke 48 patients (23\%) had a history of addictions. Weinberger's study of patients under 30 years of age with acute MI demonstrated addiction to be the only risk factor of importance, with a low prevalence of other risk factors [18]. In Adnan et al. [28] study the risk of MI and strokes between the number 10085 in the United States population ages 18 to 45 years, 46 cases of MI (5\%), and stroke 33 cases (3\%) have been reported. However, in a study of Sastry et al. [24] in Canada of addicted MI patients were more than addicted stroke patients. Sastry and Adnan studies conflict with our study. This can be different because of the abundance of males in the study that more enthusiastic to tobacco or period of time that patient expose to tobacco or smoke maybe not measure in different study; can be a factor that effect in prevalence of MI and Stroke in difference studies. The Results of this study showed that history of addictions in patients with MI was higher in males. This indicates that males are more at risk for MI. But in stroke patients was equal in both sexes. Hypertension in MI patients was more than stroke patients. DBP was higher in stroke patients in compare to MI patients. In a study of IhleHansen [26] in 210 patients with stroke, 126 cases (60\%) had hypertension. In a study of Putaala et al. [25] in 990 patients 389 (39\%) patients had hypertension. That's higher than our studies. The share of hypertension as a risk factor in studies is different looks. For hypertension that a classical vascular risk factor should not be considered as a factor. Because it can lead to cardiovascular disease and could be related to other risk factors. These risk factors can probably effect on the risk of these complications and prognosis. High-quality standardization for blood pressure measurement is needed for the comparison of blood pressure levels and for comparison of the prevalence of hypertension across countries and populations. In stroke patients studied in 52 cases (57.2\%) low-density lipoprotein (LDL) was high and in 66 cases (73.1\%) high-density lipoprotein (HDL) was low. LDL is considered an important Target for the prevention of atherosclerotic and MI [29]. In 46 patients with MI (51\%) LDL was high and the 66 patients (73\%) HDL was low. It is can be classical risk factors for MI. Regarding to the findings of abnormal blood cholesterol in MI and stroke young patients, low HDL cholesterol as a risk factor more common. On other hand LDL-lowering treatment is a potent proven method to prevent cardiovascular events [30]. Dyslipidemia is a major risk factor for atherosclerotic diseases, and serum lipid values are cornerstones in clinical risk stratification [31]. It has been clearly shown in Asian cohort studies that serum cholesterol level is positively re- lated to coronary heart disease morbidity and mortality [32]. But in our study HDL and LDL was not significant to MI. High triglycerides in 28 stroke patients (31\%) and $16 \mathrm{MI}$ patients (17\%) were observed. Some but not all studies have shown a significant association between triglycerides and coronary heart disease [33], But in our study not observed. Hyperglycemia in patients with stroke in 3 cases (3\%) and in 10 cases (11\%) of MI patients had been seen during hospitalization. The study suggests that hyperglycemia at the beginning of the disease was the most common in MI patients. History of diabetes in 8 patients (9\%) of stroke, and 9 patients with MI (10\%) was observed. That shows a history of diabetes was more than a little in MI patients. Liver enzymes in Stroke patient were investigated. ALK in MI and stroke patients in most patients were high. It can be consider an important liver index in this study. In connection with kidney laboratory tests, the BUN In stroke patients and MI patients was close together. The Creatinine in stroke patients was higher than MI patients. These findings suggest that renal dysfunction was slightly higher in stroke patients. A history of Drug abuse in both groups of patients with stroke and MI in 19 patients (21\%) had been seen, but drug abuse showed no significant relationship with the MI. Lidegard et al. [34] studied about drug abuse in women between the ages of 15 and 49 years that stroke patients were higher than MI patients only females participated in Lidegard study that was different with our study. Patients with MI and Stroke have more in males. This indicates that males with Drug abuse are more at risk for MI and stroke and show that Drug abuse can be harmful to the health of the cardiovascular system and cerebrovascular system, especially in males in compare to females.

The limitations of our study include lack of information on some well-documented risk factors such as physical inactivity and inability to account for risk factors that might have developed under follow-up. Some less well documented risk factors (e.g., thrombophilia and obstructive sleep apnea) were not routinely screened in all patients, which may cause inaccuracy in risk estimates based on the count of these risk factors and the presence of other risk factors may be have additive effects in increasing some factor, however any study with this type of comparison of risk factors, has not been done in our region.

\subsection{Conclusion}

An important feature of our results is that 4 risk factors: cardiovascular disease, diabetes, addiction and drug abuse higher in MI men patients and 2 risk factors hypertension and cerebrovascular disease in females MI patients were high. As well as in stroke patient's 3 risk factors hypertension, history of cardiovascular disease and addiction in men and in women 3 risk factors of cerebrovas- 
cular disease, diabetes and drug abuse were higher. In general, MI men patient were more at risk in compare to Stoke. From the other hand, the most common risk factor was cerebrovascular disease history, which is generally higher in women. A history of cerebrovascular disease and addiction were significant with MI. History of cardiovascular disease were significant with stroke. It is recommended that the health system works to prevent and treat these risk factors. Our finding suggest that people with a history of cerebrovascular, cardiovascular disease and addiction, consider as target society and do necessary measures lead to reduce the mortality rate. Therefore, identification of high-risk subjects warrants management with lifestyle changes and appropriate treatment. We must increase awareness of each risk factor and implement all possible policies to reduce and prevent it. Primary healthcare system must identify high-risk individuals, and policy barriers that prevent implementation of programs to lower death rate.

\section{Acknowledgments}

We appreciate and thank the department of research and technology Babol University of Medical Sciences that approve and support this work (Alijan Ahmadi Ahangar no1951) and personnel affiliated hospitals of Babol University of Medical Sciences for cooperation and assistance in this study.

\section{Footnotes}

Authors' Contribution: Alijan Ahmadi Ahangar (Corresponding author) and Mehrdad Saravi participated in the organization, the physical examination of patients, selection the candidates and interpreted the results, wrote and edited the paper. Shayan Alijanpour, Mostafa Mostafazadeh-Boora and Samaneh Hoseinalipour collected the data. Hamed Hossein Zadeh and Hemat Allah Gholinia participated in the data analysis.

Funding/Support: Babol University of Medical Science.

\section{References}

1. Wilhelmsen L, Koster M, Harmsen P, Lappas G. Differences between coronary disease and stroke in incidence, case fatality, and risk factors, but few differences in risk factors for fatal and non-fatal events. Eur Heart J. 2005;26(18):1916-22. doi: 10.1093/eurheartj/ehi412. [PubMed: 16009671].

2. Juan Z, Wei-Guo Z, Heng-Liang S, Da-Guo W. Association of Matrix Metalloproteinase 9C-1562T Polymorphism with Genetic Susceptibility to MyocardialInfarction : A Meta-Analysis. Current Therapeutic Res. 2015;77:40-5.
3. Schoenenberger AW, Radovanovic D, Stauffer JC, Windecker S, Urban $\mathrm{P}$, Niedermaier $\mathrm{G}$, et al. Acute coronary syndromes in young patients: presentation, treatment and outcome. Int J Cardiol. 2011;148(3):300-4. doi: 10.1016/j.ijcard.2009.11.009. [PubMed: 19942306].

4. Ahangar AA, Ashraf Vaghefi SB, Ramaezani M. Epidemiological evaluation of stroke in Babol, northern Iran (2001-2003). Eur Neurol. 2005;54(2):93-7. doi: 10.1159/000088643. [PubMed: 16195668].

5. Azarpazhooh MR, Etemadi MM, Donnan GA, Mokhber N, Majdi MR, Ghayour-Mobarhan M, et al. Excessive incidence of stroke in Iran: evidence from the Mashhad Stroke Incidence Study(MSIS), a populationbased study of stroke in the Middle East. Stroke. 2010;41(1):3-e10. doi: 10.1161/STROKEAHA.109.559708. [PubMed: 19926844].

6. Dehghani Firoozabadi M, Kazemi T, Sharifzadeh G, Dadbeh S, Dehghan P. Stroke in birjand, iran: a hospital-based study of acute stroke. Iran Red Crescent Med J. 2013;15(3):264-8. doi: 10.5812/ircmj.4282. [PubMed: 23984011].

7. Ueshima H, Sekikawa A, Miura K, Turin TC, Takashima N, Kita Y, et al. Cardiovascular disease and risk factors in Asia: a selected review. Circulation. 2008;118(25):2702-9. doi: 10.1161/CIRCULATIONAHA.108.790048. [PubMed: 19106393].

8. Ueshima H. Explanation for the Japanese paradox: prevention of increase in coronary heart disease and reduction in stroke.J Atheroscler Thromb. 2007;14(6):278-86. doi:10.5551/jat.E529. [PubMed: 18174657].

9. Stamler J. Established major coronary risk factors: historical overviews. Oxford, United Kingdom: Oxford University Press; 2005.

10. Ernst E. Plasma fibrinogen-an independent cardiovascular risk factor. JIntern Med. 1990;227(6):365-72. doi:10.1111/j.1365-2796.1990.tb00174.x. [PubMed: 2191070].

11. Cengel A, Tanindi A. Myocardial infarction in the young. $J$ Postgrad Med. 2009;55(4):305-13. doi:10.4103/0022-3859.58944. [PubMed: 20083887].

12. Smith BA, Grider DJ. Sudden death in a young adult: sequelae of childhood Kawasaki disease. Am J Emerg Med. 1993;11(4):381-3. doi: 10.1016/0735-6757(93)90172-8. [PubMed: 8216521].

13. Lange RA, Hillis LD. Cardiovascular complications of cocaine use. $N$ Engl J Med. 2001;345(5):351-8. doi: 10.1056/NEJM200108023450507. [PubMed: 11484693].

14. Egred M, Viswanathan G, Davis GK. Myocardial infarction in young adults. Postgrad Med J. 2005;81(962):741-5. doi: 10.1136/pgmj.2004.027532. [PubMed:16344295].

15. Saposnik G, Caplan LR, Gonzalez LA, Baird A, Dashe J, Luraschi $A$, et al. Differences in stroke subtypes among natives and caucasians in Boston and Buenos Aires. Stroke. 2000;31(10):2385-9. doi: 10.1161/01.STR.31.10.2385. [PubMed:11022068].

16. Kral M, Skoloudik D, Sanak D, Veverka T, Bartkova A, Dornak T, et al. Assessment of relationship between acute ischemic stroke and heart disease-protocol of a prospective observational trial. Biomed Pap Med Fac Univ Palacky Olomouc Czech Repub. 2012;156(3):284-9. doi: 10.5507/bp.2012.094. [PubMed: 23069890].

17. Jong-wook L. Global health improvement and WHO: shaping the future. Lancet. 2003;362(9401):2083-8. doi:10.1016/S0140-6736(03)151070. [PubMed: 14697812].

18. Kanitz MG, Giovannucci SJ, Jones JS, Mott M. Myocardial infarction in young adults: risk factors and clinical features. $J$ Emerg Med. 1996;14(2):139-45. doi: 10.1016/0736-4679(95)02089-6. [PubMed: 8740743].

19. Chua SK, Hung HF, Shyu KG, Cheng JJ, Chiu CZ, Chang CM, et al. Acute ST-elevation myocardial infarction in young patients: 15 years of experience in a single center. Clin Cardiol. 2010;33(3):140-8. doi: 10.1002/clc.20718. [PubMed: 20235218].

20. Kasper M, Fauci N, Hauser L, Longo F. Harrison's principles of internal medicine. Mc Graw Hill; 2015.

21. Putaala J, Metso AJ, Metso TM, Konkola N, Kraemer Y, Haapaniemi E, et al. Analysis of 1008 consecutive patients aged 15 to 49 with first-ever ischemic stroke: the Helsinki young stroke registry. Stroke. 2009;40(4):1195-203. doi: 10.1161/STROKEAHA.108.529883. [PubMed: 19246709]. 
22. National Cholesterol Education Program Expert Panel on Detection E, Treatment of High Blood Cholesterol in A. Third Report of the National Cholesterol Education Program (NCEP) Expert Panel on Detection, Evaluation, and Treatment of High Blood Cholesterol in Adults (Adult Treatment Panel III) final report. Circulation. 2002;106(25):3143-421. [PubMed: 12485966].

23. Chobanian AV, Bakris GL, Black HR, Cushman WC, Green LA, Izzo JJ, et al. Seventh report of the Joint National Committee on Prevention, Detection, Evaluation, and Treatment of High Blood Pressure. Hypertension. 2003;42(6):1206-52. doi: 10.1161/01.HYP.0000107251.49515.c2. [PubMed: 14656957].

24. Sastry S, Riding G, Morris J, Taberner D, Cherry N, Heagerty A, et al. Young Adult Myocardial Infarction and Ischemic Stroke: the role of paradoxical embolism and thrombophilia (The YAMIS Study). $J$ Am Coll Cardiol. 2006;48(4):686-91. doi: 10.1016/j.jacc.2006.02.074. [PubMed: 16904535].

25. Putaala J, Haapaniemi E, Kaste M, Tatlisumak T. How does number of risk factors affect prognosis in young patients with ischemic stroke? Stroke. 2012;43(2):356-61. doi:10.1161/STROKEAHA.111.635276. [PubMed: 22052508].

26. Ihle-Hansen H, Thommessen B, Wyller TB, Engedal K, Fure B. Risk factors for and incidence of subtypes of ischemic stroke. Funct Neurol. 2012;27(1):35-40. [PubMed: 22687165].

27. Siegerink B, Meltzer ME, de Groot PG, Algra A, Lisman T, Rosendaal FR. Clot lysis time and the risk of myocardial infarction and ischaemic stroke in young women; results from the RATIO case-control study. Br J Haematol. 2012;156(2):252-8. doi: 10.1111/j.1365-2141.2011.08935.x. [PubMed: 22082241].

28. Adnan I, Qureshi M, Fareed K, Guterman L. Cocaine Use and the Likelihood of Nonfatal Myocardial Infarction and Stroke Third National Health and Nutrition Examination Survey. USA:Am Heart Association;
2012

29. Ebisawa S, Izawa A, Ueki Y, Hioki H, Minamisawa M, Hashizume N. Impact of combination therapy with statin and ezetimibe on secondary prevention for post-acute myocardial infarction patients in the statin era. Int J Cardiol Heart \& Vasculature. 2015;8:154-60. doi 10.1016/j.ijcha.2015.07.007.

30. McQueen MJ, Hawken S, Wang X, Ounpuu S, Sniderman A, Probstfield J, et al. Lipids, lipoproteins, and apolipoproteins as risk markers of myocardial infarction in 52 countries (the INTERHEART study): a case-control study. Lancet. 2008;372(9634):224-33. doi: 10.1016/S01406736(08)61076-4. [PubMed: 18640459].

31. Juonala M, Viikari JS, Kahonen M, Solakivi T, Helenius H, Jula A, et al. Childhood levels of serum apolipoproteins B and A-I predict carotid intima-media thickness and brachial endothelial function in adulthood: the cardiovascular risk in young Finns study. J Am Coll Cardiol. 2008;52(4):293-9. doi: 10.1016/j.jacc.2008.03.054. [PubMed: 18634985].

32. Lavados PM, Sacks C, Prina L, Escobar A, Tossi C, Araya F, et al. Incidence, 30-day case-fatality rate, and prognosis of stroke in Iquique, Chile: a 2-year community-based prospective study (PISCIS project). Lancet. 2005;365(9478):2206-15. doi: 10.1016/S0140-6736(05)66779-7. [PubMed: 15978929].

33. John K, Gilbert L, Michael H, Joanna L, Gams A, Roland S. Association of the Metabolic Syndrome With History of Myocardial Infarction and Stroke in the Third National Health and Nutrition Examination Survey. Circulation. 2004;109:42-6.

34. Lidegaard O, Lokkegaard E, Jensen A, Skovlund CW, Keiding N. Thrombotic stroke and myocardial infarction with hormonal contraception. N Engl J Med. 2012;366(24):2257-66. doi: 10.1056/NEJMoa1111840. [PubMed: 22693997]. 